\title{
CrimRxiv
}

\section{Science of Societal Safety: Living at Times of Risks and Disasters}

Seiji Abe, Mamoru Ozawa

Published on: Mar 03, 2022

License: Creative Commons Attribution 4.0 International License (CC-BY 4.0). 
